\title{
Selenium isotope evidence for pulsed flow of oxidative slab fluids
}

\author{
S. König ${ }^{1 *}$, C. Rosca1, T. Kurzawa1 ${ }^{1}$ M.I. Varas-Reus ${ }^{1}$, \\ B. Dragovic ${ }^{2}$, R. Schoenberg ${ }^{1,3}$, T. John ${ }^{4}$
}

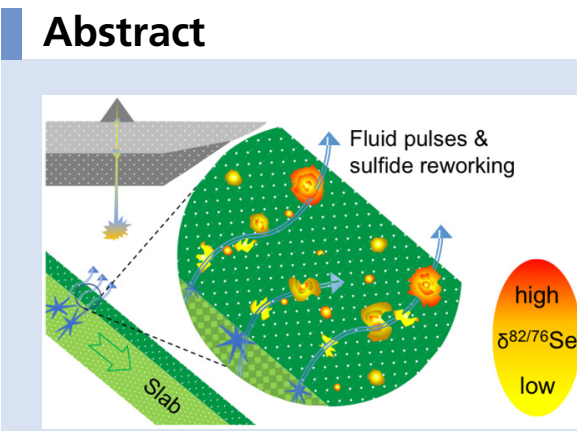

sulfide reworking within the subducted crust can be reconciled with episodes of oxidised fluid pulses from underlying slab mantle in modern subduction zones.

Received 20 October 2020 | Accepted 13 February 2021 | Published 9 March 2021

\section{Introduction}

The development of a habitable Earth with its atmosphere-ocean system is closely linked to plate tectonics and the efficient exchange of elements between interior and exterior reservoirs. Key aspects are the subduction cycles of water, carbon and sulfur and the redox state of arc magmas. It is particularly debated if the oxidised nature of arc magmas is due to oxidised slab components or related to secondary processes during the evolution of arc melts (e.g., Lee et al., 2012; Chen et al., 2019; Tollan and Hermann, 2019). Likewise, different models for sulfate- and ${ }^{34} \mathrm{~S}$-enriched arc lavas involve either slab-derived sulfur flux into the overlying mantle wedge or crustal assimilation by ascending magma (e.g., Lee et al., 2012; Pons et al., 2016). Recent in situ S isotope investigations of sulfides from exhumed high pressure rocks reveal prograde subduction related mobilisation and reentrapment of $S$ during (partial) sulfide breakdown and recrystallisation, resulting in differences in $\delta^{34} \mathrm{~S}$ of almost $40 \%$ o (Evans et al., 2014; Su et al., 2019; Li et al., 2020; Walters et al., 2020), with contrasting data for different localities suggesting either oxidised, $\mathrm{SO}_{2}$ - and $\mathrm{CO}_{2}$-rich or reduced, $\mathrm{H}_{2} \mathrm{~S}$-rich fluid involvement (see also Piccoli et al., 2019).

To further elucidate the redox role of slab-derived components, we combine the novel tool of stable selenium isotopes with a suite of well characterised high pressure rocks of oceanic origin. In comparison to other redox sensitive elements like Mo, $\mathrm{S}$ and $\mathrm{Fe}$, Se combines the characteristics of being chalcophile and a trace element that does not act as a major constituent of sulfide. Selenium, therefore, participates in sulfide dissolution-recrystallisation processes within the slab as a witness without being biased as a major constituent of a mineral. Moreover, the transition to selenite (oxidised Se species; $\mathrm{SeO}_{3}^{2-}$; see S-Se species stability fields in Fig. 1) occurs at even higher $\mathrm{fO}_{2}$ compared to the transition to sulfate (oxidised S species; $\mathrm{SO}_{4}^{2-}$ ). Thus, Se isotope fractionation reflects a strong reduction of at least selenite to selenide from originally higher $\mathrm{fO}_{2}$ than the sulfatesulfide transition (Fig. 1). Selenium isotopes may thus be useful in constraining the conditions during slab fluid-mediated sulfide redistribution, in particular, if more pronounced redox variations occur in fluids that so far remained beyond the scope of $\mathrm{S}$ isotope systematics (König et al., 2019) and previously employed, lithophile (e.g., Mo-Li-N-Tl) stable isotopes in subduction related studies.

The Raspas Complex in SW Ecuador resembles a deeply subducted $(\sim 60 \mathrm{~km})$ ophiolite complex that formed during the early Cretaceous at the South American margin. Trace element and radiogenic isotope data revealed that the ophiolite consists of depleted abyssal oceanic mantle, oceanic crust (MORB-type eclogites), associated seamounts (blueschists), and sedimentary cover (John et al., 2010; Halama et al., 2011). The entire complex was metamorphosed at HP/LT conditions $\left(\sim 600^{\circ} \mathrm{C}\right.$ and $c a .2 .0$ $\mathrm{GPa}$ ) and most of the rocks experienced subduction related, prograde dehydration related intra-slab fluid flow during burial (John et al., 2010; Halama et al., 2011; Herms et al., 2012;

\footnotetext{
Isotope Geochemistry Group, Dept. of Earth Sciences, University of Tuebingen, Germany

School of the Earth, Ocean and Environment, University of South Carolina, USA

Department of Geology, University of Johannesburg, South Africa

Institut für Geologische Wissenschaften, Freie Universitaet Berlin, Germany

Corresponding author (email: stephan.koenig@uni-tuebingen.de; timm.john@fu-berlin.de)
} 


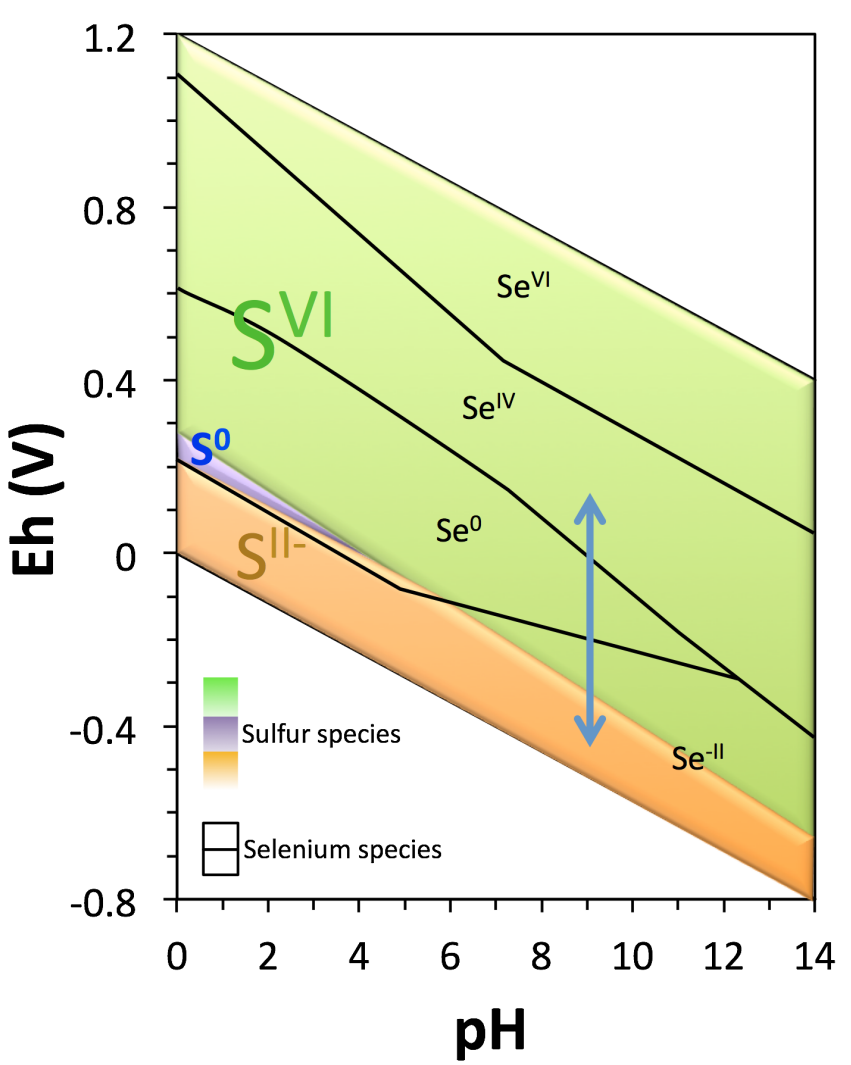

Figure 1 Combined $\mathrm{S}$ and Se Pourbaix diagrams for $25^{\circ} \mathrm{C}$ and 1 bar pressure. Large arrow shows required minimum redox variation for selenite-selenide transition that requires higher redox variation than the sulfide-sulfate transition for slab fluids with $\mathrm{pH}$ of up to 9 in subduction zones (Galvez et al., 2016).

Chen et al., 2019; Urann et al., 2020). The Raspas complex thus represents an exceptional example of a rather complete sequence of an oceanic lithosphere that has experienced long lived oceanic subduction and is not compromised by potential effects of subsequent continent-continent collision.

\section{Samples}

The samples analysed here comprise seven eclogites, one metapelite, and three high pressure serpentinites from the Raspas Complex (Supplementary Information Tables S-1 and S-2). They have been thoroughly investigated for their petrology and all samples record evidence for hydration prior to subduction, but have been mostly selected to avoid any detectable exhumation related overprint (John et al., 2010; Halama et al., 2011; Herms et al., 2012). A comprehensive major, trace element, $\mathrm{Rb}-\mathrm{Sr}$, $\mathrm{Sm}-\mathrm{Nd}$, Lu-Hf geochronological and stable Mo-Li-N-Tl isotope dataset is also available (e.g., Halama et al., 2010; John et al., 2010; Chen et al., 2019; Su et al., 2019). We also analysed four serpentinites and gabbros from the deepest Pacific drillcore available (IODP-1256D; Table S-1). We combine this sample set with an average composition of marine sediment from the literature to provide a reliable estimate of subduction input signatures.

\section{Selenium Isotope Signatures of Prograde Metamorphic Rocks}

Compared to the relatively small range for mantle samples including average MORB with $\delta^{82 / 76} \mathrm{Se} \quad\left(\delta^{82 / 76} \mathrm{Se}=\left[\left({ }^{82} \mathrm{Se} /\right.\right.\right.$ $\left.\left.\left.{ }^{76} \mathrm{Se}\right)_{\text {sample }} /\left({ }^{82} \mathrm{Se} /{ }^{76} \mathrm{Se}\right)_{\mathrm{NIST} 3149}-1\right] \times 1000\right)$ of $-0.16 \pm 0.12 \%$
(2 s.d.; Yierpan et al., 2019), peridotites of $-0.03 \pm 0.07 \%$ (Varas-Reus et al., 2019) and the limited variability observed in seawater overprinted altered ocean crust (AOC) with $\delta^{82 / 76} \mathrm{Se}$ of -0.35 to $-0.07 \%$ o (Pacific drillcore samples; Table S-1), eclogites record a large variation in $\delta^{82 / 76}$ Se from -1.89 to $+0.48 \%$ o (Fig. 2; see Supplementary Information for analytical methods). High pressure serpentinites and metapelites show $\delta^{82 / 76} \mathrm{Se}$ of +0.07 to $+0.39 \%$, overlapping with the highest $\delta^{82 / 76}$ Se values of eclogites. $\delta^{82 / 76}$ Se values show no systematic variations with

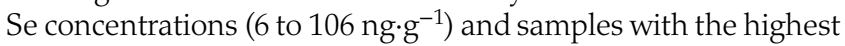
Se contents span the entire Se isotope range of the dataset. High pressure serpentinites show highest relative abundances of fluid mobile elements like $\mathrm{Pb}, \mathrm{Rb}, \mathrm{Cs}$ (Fig. 2a-c) or $\mathrm{Ba}, \mathrm{Li}$ (not shown) when plotted as ratios with fluid immobile Ce as the denominator (see also Fig. S-1). All eclogites show a trend towards lower $\delta^{82 / 76} \mathrm{Se}$ with decreasing $\mathrm{Pb} / \mathrm{Ce}, \mathrm{Rb} / \mathrm{Ce}$ and $\mathrm{Cs} / \mathrm{Ce}$ (Fig. 2a). Eclogites with the lowest $\delta^{82 / 76}$ Se sample also display the lowest $\delta^{98 / 95} \mathrm{Mo}$ (Fig. 2d; Mo data by Chen et al., 2019) but two samples with only intermediate $\delta^{98 / 95}$ Mo show the most positive $\delta^{82 / 76}$ Se. Additionally, eclogites with the lowest $\delta^{82 / 76}$ Se show the highest contents of $\mathrm{Cu}, \mathrm{Cl}$, Sc (Fig. 3) and $\mathrm{N}$ as well as the smallest $\delta^{15} \mathrm{~N}$ range (Fig. S-2; Halama et al., 2010; Urann et al., 2020). No correlations between $\delta^{82 / 76} \mathrm{Se}$ and $\mathrm{Li}$ or $\mathrm{Tl}$ isotopes are observed (Fig. S-2).

\section{Selenium Isotope Vestige of Slab Dehydration}

Selenium isotopes do not fractionate significantly during melting, fractional crystallisation and metasomatism (Varas-Reus et al., 2019; Yierpan et al., 2019). The $\delta^{82 / 76}$ Se range of eclogites and clear positive covariations of $\delta^{82 / 76}$ Se with several fluid proxies (Fig. $2 \mathrm{a}-\mathrm{c}$ ) therefore suggest a non-magmatic origin of these signatures. Moreover, since the eclogite facies mineral assemblages show no evidence of subsequent retrograde greenschist facies overprint (except for one sample selected here; John et al., 2010; Herms et al., 2012), the $\delta^{82 / 76}$ Se and their preserved fluid related trends must be attributed to dehydration processes prior to exhumation. Analysed AOC extends to slightly lower $\delta^{82 / 76} \mathrm{Se}$ and the high pressure serpentinites to slightly higher $\delta^{82 / 76} \mathrm{Se}$ than mantle, while both assemblages maintain a much narrower range than the eclogites. Light $\mathrm{S}$ isotope compositions of pyrite in subducted rocks from SW Tianshan, China could be traced back to the alteration of oceanic crust and subsequent, fluid driven sulfide recrystallisation events with prograde metamorphism (Su et al., 2019). Such abyssal seawater-rock interaction therefore also explains the low average $\delta^{82 / 76} \mathrm{Se}$ in our AOC, due to scavenging related partial reduction of preferentially light Se isotopes in an entirely oxic water column (e.g., Johnson, 2004). In conclusion, following subduction of AOC with moderately low $\delta^{82 / 76} \mathrm{Se}$, higher $\delta^{82 / 76} \mathrm{Se}$ of the high pressure serpentinites as well as the large $\delta^{82 / 76}$ Se range of the eclogites are best explained by slab dehydration during prograde metamorphism at the blueschist-eclogite transition.

\section{Role of Oxidised Slab Fluids}

In fluid-solid systems, isotopes of Se are significantly fractionated during partial reduction of oxidised $\mathrm{Se}^{6+}$ to $\mathrm{Se}^{4+}$ or further to $\mathrm{Se}^{2-}$ (Johnson, 2004). Sulfides thus preferentially incorporate isotopically light Se (e.g., König et al., 2019). Even at $25^{\circ} \mathrm{C}$ and $1 \mathrm{~atm}$, the transition from $\mathrm{Se}^{2-}$ to $\mathrm{Se}^{0}$ and $\mathrm{Se}^{4+}$ starts at higher redox potential (Eh) and thus require higher $\mathrm{fO}_{2}$ than the sulfide-sulfate transition (Fig. 1). This difference remains with slightly elevated slab fluid $\mathrm{pH}$ of up to 9 in subduction zones 


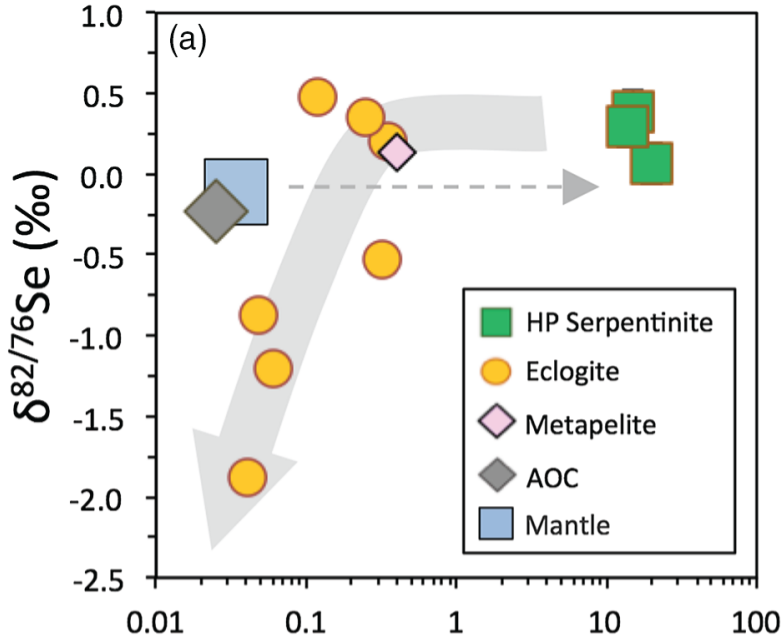

$\mathrm{Pb} / \mathrm{Ce}$

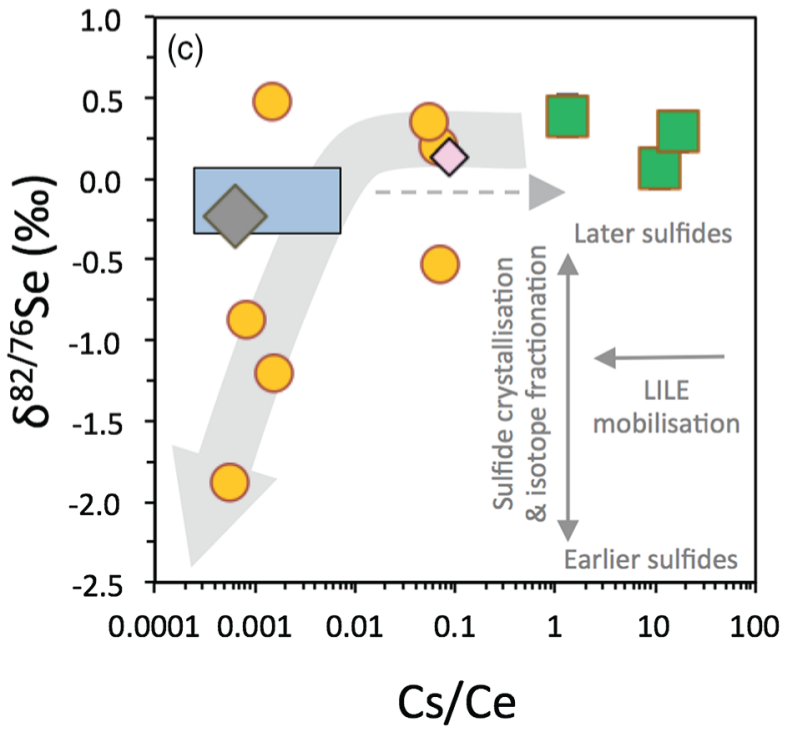

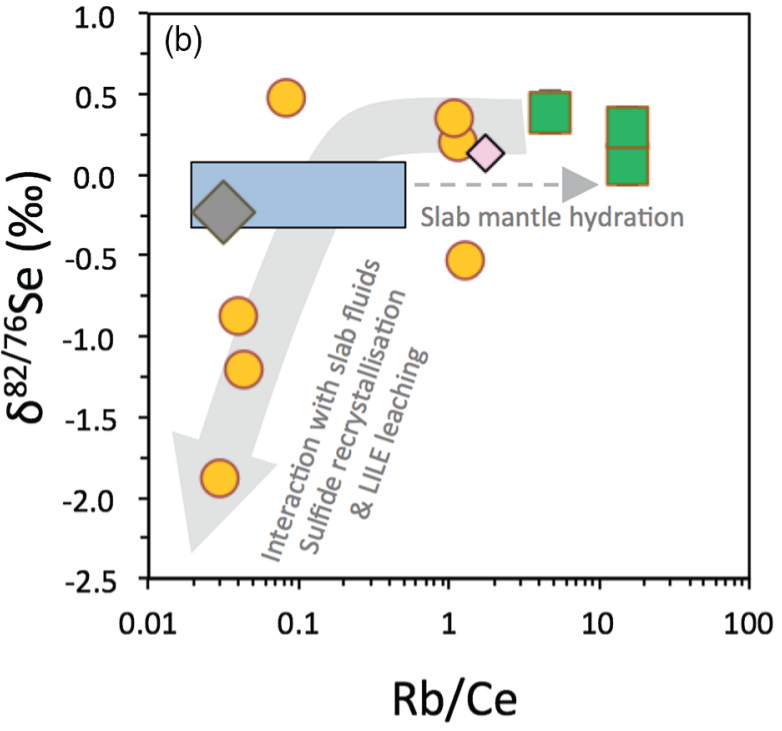

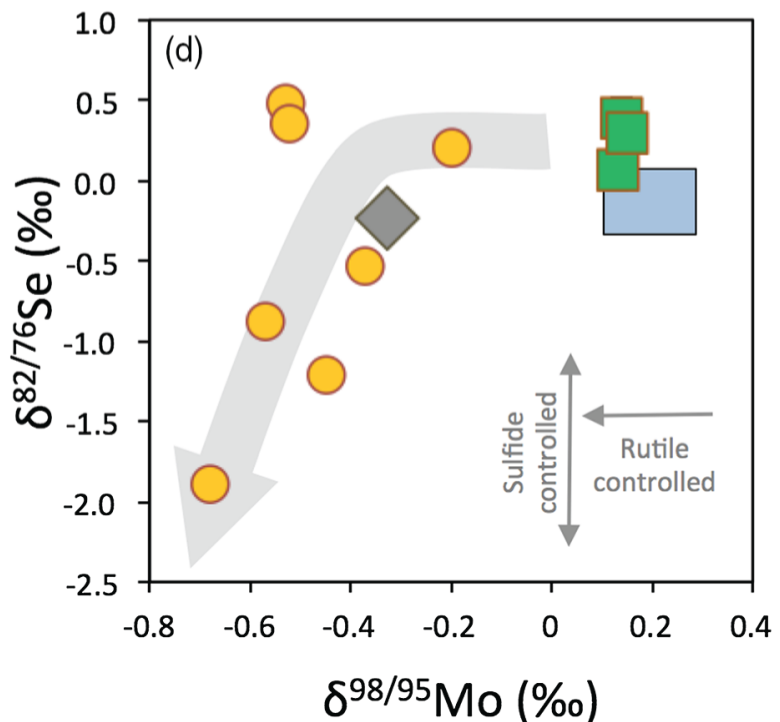

Figure 2 Selenium isotope composition of Raspas samples and AOC from 1256D vs. (a) Pb/Ce, (b) Rb/Ce, and (c) Cs/Ce (Halama et al., 2010; John et al., 2010), and (d) $\delta^{98 / 95}$ Mo variation. Mantle includes representative peridotites (Varas-Reus et al., 2019) and MORB (Yierpan et al., 2020). The large grey arrow (Figs. 2, 3) represents our interpretation of the effects of slab mantle dehydration and increasing interaction of subducted crust with slab fluids. The source of Mo is HP serpentinite (Chen et al., 2019), whereas Se is derived mostly from the AOC. As HP serpentinites dehydrate and flush the overlying subducted AOC, rutiles in the subducted crust preferentially retain low $\delta^{98 / 95}$ Mo as the complementary, high $\delta^{98 / 95}$ Mo fluid is removed into the mantle wedge (Freymuth et al., 2015; Chen et al., 2019). Recrystallising, early sulfides preferentially incorporate light Se isotopes and later stage sulfides become isotopically heavier. Repeated sulfide dissolutionrecrystallisation produces a spectrum of low and high $\delta^{82 / 76} \mathrm{Se}$ in the flushed AOC.

(Galvez et al., 2016). At present, $\mathrm{Se}^{6+} / \Sigma \mathrm{Se}$ equilibrium values for substantially higher temperatures and pressures are unavailable and therefore the quantification of $\mathrm{fO}_{2}$ from the inferred presence of oxidised Se in slab fluids requires further experimental work. However, such experimentally derived constants exist for $S^{6+} / \sum S$ and were previously used to infer a range of slab fluid FMQ of +1.0 to +1.4 at $1.5 \mathrm{GPa}$ from observed sulfate as well as anhydrite saturation in sub-arc mantle peridotites and melt inclusions (Bénard et al., 2018). The sulfate-sulfide transition at conditions relevant to the Raspas eclogite suite at $2 \mathrm{GPa}$ and $600{ }^{\circ} \mathrm{C}$ requires $\mathrm{ca}$. FMQ +2.5 . If significant $\Delta$ Eh between lower sulfate and selenite stabilities persist at $600^{\circ} \mathrm{C}$ and $2 \mathrm{GPa}$, the occurrence of oxidised Se points to above FMQ +2 for slab fluids involved here. This would agree with previous estimates for slab fluid $\mathrm{fO}_{2}$ above FMQ +2 based on Mo isotope data of Raspas eclogites (Chen et al., 2019). More accurate constraints require experimental work, yet Se isotope data can already be attributed to more pronounced minimum redox variations than those required for stability of oxidised S and even Mo in the subducting slab, as supported by other studies arguing for variably pronounced oxidation potentials of fluids in subduction zones (e.g., Bénard et al., 2018; Chen et al., 2019; Piccoli et al., 2019; Li et al., 2020; Walters et al., 2020).

\section{Sulfide Dissolution-Recrystallisation}

High pressure, intra-slab fluid flow occurs as channelised and in pulses, variably affecting slab mineralogy (e.g., Herms et al., 2012; John et al., 2012; Chen et al., 2019). The lack of systematic covariations between $\delta^{82 / 76} \mathrm{Se}$ and other stable isotope signatures of $\mathrm{Li}, \mathrm{N}$, and $\mathrm{Tl}$ in Raspas eclogites points to different controls on each isotope signature. Kinetically controlled Li isotope fractionation is related to diffusion during fluid-rock interaction 

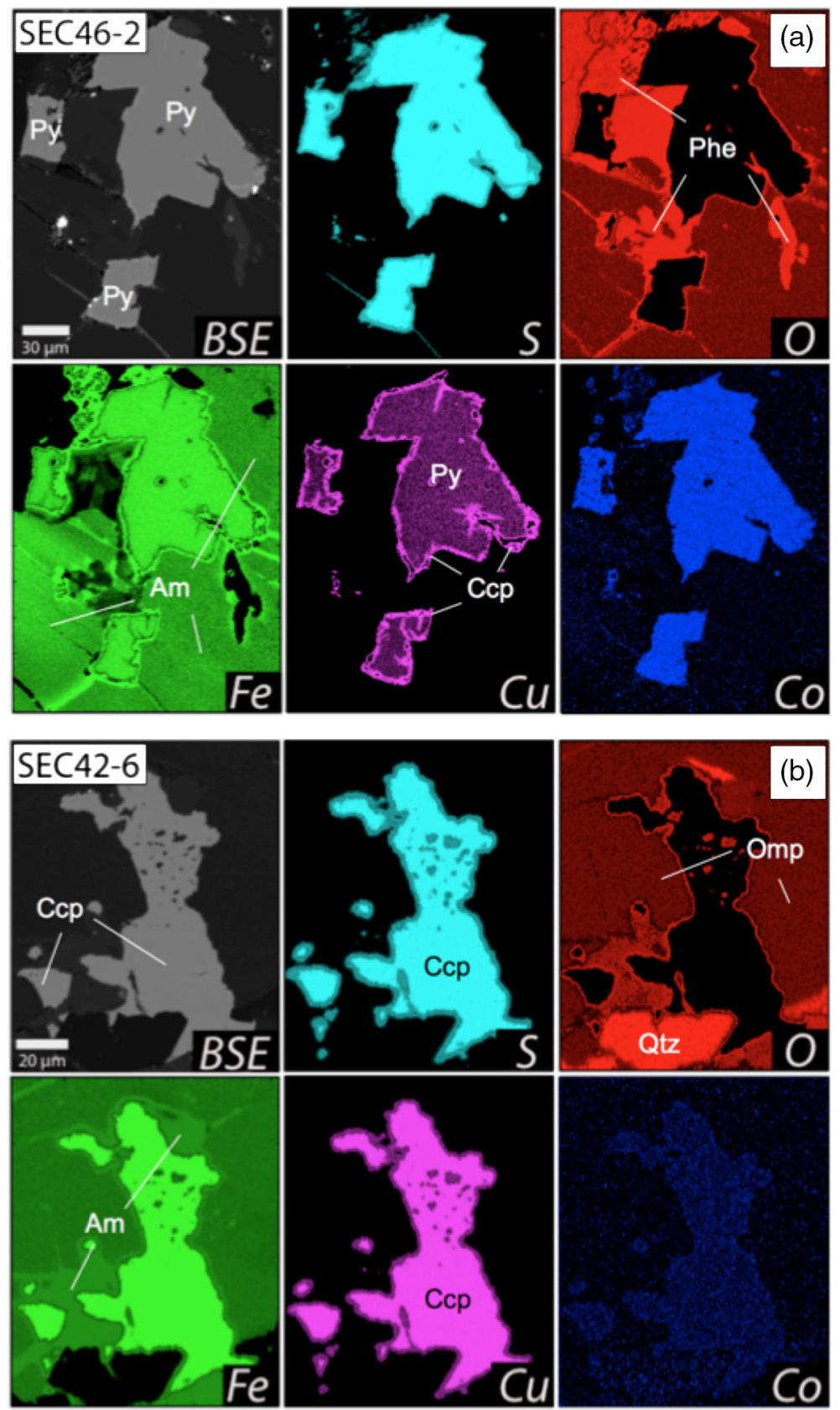
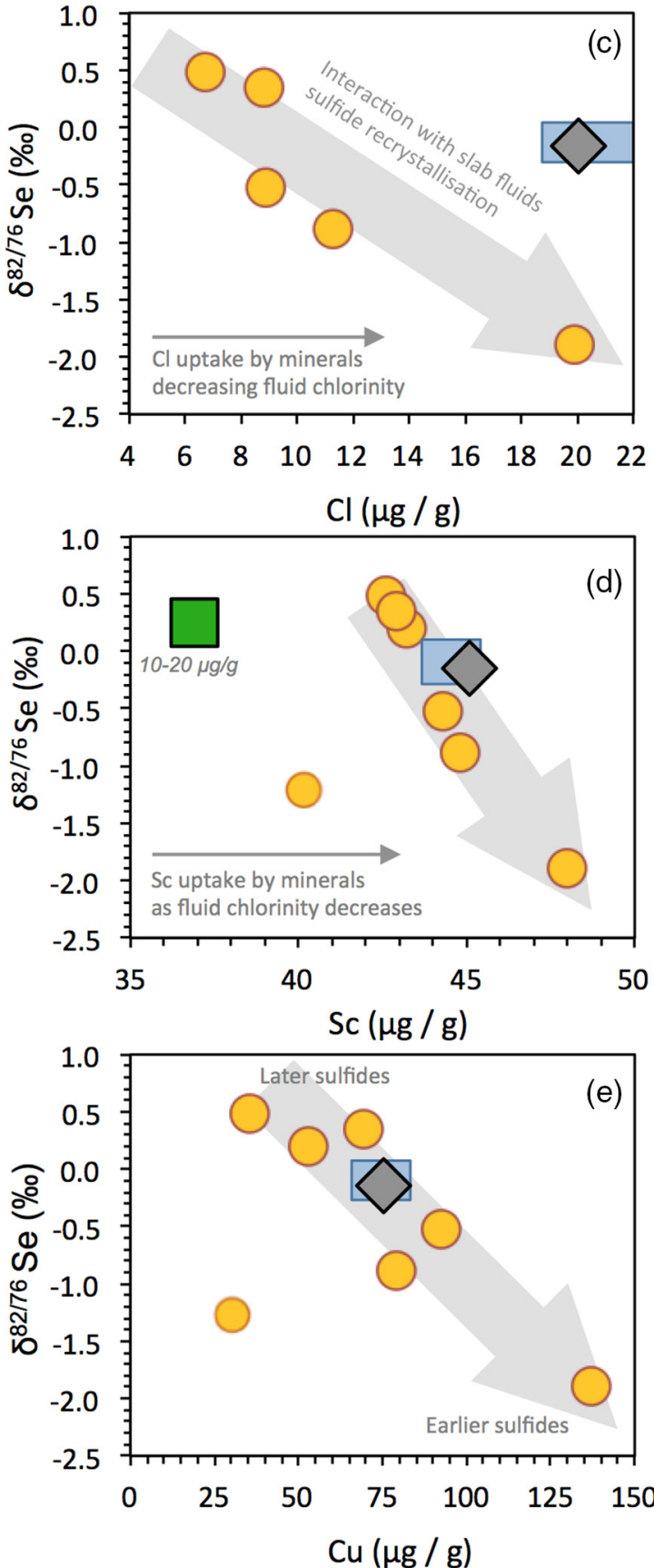

Figure 3 BSE images and semi-quantitative element mapping of sulfides in Raspas eclogites: (a) a partially resorbed Co-bearing pyrite, showing high $\mathrm{Cu}$ and $\mathrm{Fe}$ contents at the recrystallised chalcopyrite rim and (b) an example of a chalcopyrite with a narrow and oxidised rim, indicated by the lower S and Cu contents. Trends of $8^{82 / 76} \mathrm{Se}$ vs. concentrations of (c) Cl, (d) Sc and (e) Cu in prograde eclogites are interpreted to result from this changing fluid-mineral chemistry. Symbols are the same as those used in Figure 2.

(Halama et al., 2011). Lighter $\mathrm{N}$ and $\mathrm{Tl}$ isotope signatures of Raspas eclogites compared to MORB indicate preservation of low temperature AOC signatures during subduction (Halama et al., 2010; Shu et al., 2019). In contrast to these lithophile element based isotope systems, chalcophile Se substitutes for $\mathrm{S}$ in sulfides and witnesses repeated sulfide dissolutionrecrystallisation events as fluids pulse through the slab (Evans et al., 2014; Su et al., 2019; Li et al., 2020). This is supported by the mineral assemblages of the eclogites that show sulfides in different stages of dissolution and recrystallisation (Fig. 3a,b) and covariations between $\delta^{82 / 76}$ Se and trace elements (Fig. 3c-e). Eclogite 46-2, for which a partially recrystallised pyrite with highest Co contents and high $\mathrm{Cu}$ (chalcopyrite) rims is shown
(Fig. 3a), has the lowest bulk $\delta^{82 / 76}$ Se and highest $\mathrm{Cl}$ contents (Fig. 3c). This sample also contains abundant apatite, with up to $300 \mu \mathrm{g} \cdot \mathrm{g}^{-1} \mathrm{Cl}$ (Urann et al., 2020), suggesting that breakdown of hydrous $\mathrm{Cl}$ complexes, possibly cause co-precipitation of cations like Sc that partition into matrix minerals (e.g., Sc into omphacite and garnet, Fig. 3d). This coincides with recrystallisation of sulfides that increase $\mathrm{Cu}$ contents in eclogites (Fig. 3a,e). Whereas Mo isotopes in the bulk eclogites record the integrated and unidirectional signature of interaction between fluid and rutile-bearing rocks (Fig. 2d; Chen et al., 2019), $\delta^{82 / 76}$ Se signatures in subducted rocks seem to capture snapshots of repeated and localised sulfide dissolution-recrystallisation effects during highly oxidised, channelised intra-slab fluid flow. 
We compared our data to closed system equilibrium and Rayleigh-type fractionation models, which express Se isotope behaviour during partial reduction of Se incorporated into (re)-crystallising sulfides from migrating slab fluids. Sulfides that partly dissolve, recrystallise and dissolve again are neither entirely removed nor fully remixed into the system and hence neither closed nor open system Rayleigh fractionation alone, but a combination of the two can adequately express the entire natural process. This was also previously inferred for such prograde metamorphic conditions for S isotopes (Evans et al., 2014; Supplementary Information and Fig. S-3). As such, the result of repeated sulfide dissolution-recrystallisation cycles during continuous and pulsed fluid flow is the most plausible scenario that generates the $\delta^{82 / 76} \mathrm{Se}$ spectrum of eclogites. This encompasses low $\delta^{82 / 76}$ Se for early stage, only partially re-dissolved sulfides and high values for late stage and/or significantly reworked, i.e. re-dissolved sulfides (Figs. 2, 3, S-3).

\section{Implications for the Se Subduction Cycle}

Our Se data can be reconciled with a repetitive cycle of sulfide dissolution and recrystallisation during oxidising fluid flow through the subducted AOC as previously suggested for $\mathrm{S}$ (e.g., Evans et al., 2014; Su et al., 2019). Small scale Se isotope heterogeneities are however likely re-homogenised at the slab scale with continuous sulfide reworking (see Graphical Abstract). We therefore speculate that any significant volume of Se, and by analogy also S, that ultimately crosses the slabmantle wedge zone into the sub-arc mantle might not be isotopically distinct from an initial subduction input. In other words, considering the big picture mass balance, slab dehydration may affect the mass fraction of Se without necessarily affecting its isotope signature. Preservation of the overall isotope signature of the slab, which is further subducted into the deeper mantle, is able to explain high $\delta^{82 / 76} \mathrm{Se}$ of plume-related lavas that trace recycled sedimentary components subducted from a redox stratified Proterozoic ocean (Yierpan et al., 2020), as well as low $\delta^{82 / 76}$ Se of Mariana arc lavas that include recycled materials subducted from a fully oxygenated modern ocean (Kurzawa et al., 2019).

\section{Acknowledgements}

SK acknowledges ERC Starting Grant O2RIGIN (636808). $\mathrm{M}$. Liesegang is thanked for EPMA support and IODP for the drillcore samples. Helpful comments by two reviewers and particularly editor $\mathrm{H}$. Marschall significantly improved this contribution.

Editor: Horst R. Marschall

\section{Additional Information}

Supplementary Information accompanies this letter at https:// www.geochemicalperspectivesletters.org/article2110.

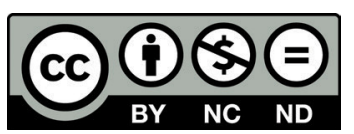

(C) 2021 The Authors. This work is distributed under the Creative Commons Attribution NonCommercial No-Derivatives 4.0 License, which permits unrestricted distribution provided the original author and source are credited. The material may not be adapted (remixed, transformed or built upon) or used for commercial purposes without written permission from the author. Additional information is available at https://www. geochemicalperspectivesletters.org/copyright-and-permissions.
Cite this letter as: König, S., Rosca, C., Kurzawa, T., VarasReus, M.I., Dragovic, B., Schoenberg, R., John, T. (2021) Selenium isotope evidence for pulsed flow of oxidative slab fluids. Geochem. Persp. Let. 17, 27-32.

\section{References}

Bénard, A., Klimm, K., Woodland, A.B., Arculus, R.J., Wilke, M., Botcharnikov, R.E., Shimizu, N., Nebel, O., Rivard, C., Ionov, D.A. (2018) Oxidising agents in sub-arc mantle melts link slab devolatilisation and arc magmas. Nature Communications 9, 3500.

Chen, S., Hin, R.C., John, T., Brooker, R., Bryan, B., Niu, Y., Elliott, T. (2019) Molybdenum systematics of subducted crust record reactive fluid flow from underlying slab serpentine dehydration. Nature Communications 10, 4773.

Evans, K.A., Tomkins, A.G., ClifF, J. Fiorentini, M.L. (2014) Insights into subduction zone sulfur recycling from isotopic analysis of eclogite-hosted sulphides. Chemical Geology 365, 1-19.

Freymuth, H., Vils, F., Willbold, M., Taylor, R.N., Elliott, T. (2015) Molybdenum mobility and isotopic fractionation during subduction at the Mariana arc. Earth and Planetary Science Letters 432, 176-186.

Galvez, M.E., Connolly, J.A.D., Manning, C.E. (2016) Implications for metal and volatile cycles from the $\mathrm{pH}$ of subduction zone fluids. Nature 539, 420-424.

Halama, R., Bebout, G.E., John, T., Schenk, V. (2010) Nitrogen recycling in subducted oceanic lithosphere: The record in high- and ultrahigh-pressure metabasaltic rocks. Geochimica et Cosmochimica Acta 74, 1636-1652.

Halama, R., John, T., Herms, P., Hauff, F., Schenk, V. (2011) A stable (Li, O) and radiogenic $(\mathrm{Sr}, \mathrm{Nd})$ isotope perspective on metasomatic processes in a subducting slab. Chemical Geology 281, 151-166.

HeRms, P., John, T., BAKKER, R.J., SchENK, V. (2012) Evidence for channelized external fluid flow and element transfer in subducting slabs (Raspas Complex, Ecuador). Chemical Geology 310-311, 79-96.

John, T., Scherer, E.E., Schenk, V., Herms, P., Halama, R., Garbe-SchonberG, D. (2010) Subducted seamounts in an eclogite-facies ophiolite sequence: the Andean Raspas Complex, SW Ecuador. Contributions to Mineralogy and Petrology 159, 265-284

John, T., Gussone, N., Podladchikov, Yy, Bebout, G.E, Dohmen, R, Halama, R, Klemd, R., Magna, T., SeItz, H.-M. (2012) Volcanic arcs fed by rapid pulsed fluid flow through subducting slabs. Nature Geoscience 5, 489-492.

JoHNSON, T.M. (2004) A review of mass-dependent fractionation of selenium isotopes and implications for other heavy stable isotopes. Chemical Geology 204, 201-214.

König, S., Eickmann, B., Zack, T., Yierpan, A., Wille, M., Taubald, H., SCHOENBERG, R. (2019) Redox induced sulfur-selenium isotope decoupling recorded in pyrite. Geochimica et Cosmochimica Acta 244, 24-39.

KurZawa, T., König, S., Alt, J.C., Yierpan, A., Schoenberg, R. (2019) The role of subduction recycling on the selenium isotope signature of the mantle: Constraints from Mariana arc lavas. Chemical Geology 513, 239-249.

Lee, C.-T., Luffi, A.P., Chin, E.J., Bouchet, R., Dasgupta, R., Morton, D.M., Le Roux, V., YIN, Q.-Z., JiN, D. (2012) Copper systematics in arc magmas and implications for crust-mantle differentiation. Science 336, 64-68.

Li, J.-L., Schwarzenbach, E.M., John, T., Ague, J.J., Huang, F., GaO, J., Klemd, R., Whitehouse, M.J., WANG, X.-S. (2020) Uncovering and quantifying the subduction zone sulfur cycle from the slab perspective. Nature Communications 11,514

Piccoli, F., Hermann, J., PettKe, T., Connolly, J.A.D., Kempf, E.D., Vieira Duarte, J.F. (2019) Subducting serpentinites release reduced, not oxidized, aqueous fluids. Scientific Reports 9, 19573.

Pons, M.L., Debret, B., Boullhol, P., Delacour, A., Williams, H. (2016) Zinc isotope evidence for sulfate-rich fluid transfer across subduction zones. Nature Communications 7, 13794

Shu, Y., Nielsen, S.G., Marschall, H.R., John, T., Blusztajn, J., Auro, M. (2019) Closing the loop: subducted eclogites match thallium isotope compositions of ocean island basalts. Geochimica et Cosmochimica Acta 250, 130-148.

Su, W., Schwarzenbach, E., Chen, L., Li, Y., John, T., Gao, J., Chen, F., Hu, X. (2019) Sulfur isotope compositions of pyrite from high-pressure metamorphic rocks and related veins (SW Tianshan, China): Implications for the sulfur cycle in subduction zones. Lithos 348-349, 105212

Tollan, P., Hermann, J. (2019) Arc magmas oxidized by water dissociation and hydrogen incorporation in orthopyroxene. Nature Geoscience 12, 667-671.

Urann, B.M., Le Roux, V., John, T., Beaudoin, G.M., Barnes, J.D. (2020) The distribution and abundance of halogens in eclogites: An in situ SIMS perspective of the Raspas Complex (Ecuador). American Mineralogist 105, 307-318. 
Varas-Reus, M.I., König, S., Yierpan, A., Lorand, J.-P., Schoenberg, R. (2019) Selenium isotopes as tracers of a late volatile contribution to Earth from the outer Solar System. Nature Geoscience 12, 779-782.

Walters, J.B., Cruz-Uribe, A.M., Marschall, H.R. (2020) Sulfur loss from subducted altered oceanic crust and implications for mantle oxidation. Geochemical Perspectives Letters 13, 36-41.

Yierpan, A., König, S., Labidi, J., SchoenberG, R. (2019) Selenium isotope and S-Se-Te elemental systematics along the Pacific-Antarctic ridge: Role of mantle processes. Geochimica et Cosmochimica Acta 249, 199-224.

Yierpan, A., König, S., Labidi, J., Schoenberg, R. (2020) Recycled selenium in hot spot-influenced lavas records ocean-atmosphere oxygenation. Science Advances 6, eabb6179. 